\section{THE METALLOGRAPHY OF IRON AND} IRON-CARBON ALLOYS.

$A^{T}$ the May meeting of the Iron and Steel Institute two papers of decided scientific importance were presented. In one of these Prof. G. Cesarò, of Liège University, a distinguished Belgian man of science, has endeavoured by careful mathematical analysis to ascertain the course of the curve joining the points at which molten iron-carbon alloys commence to solidify, if the abscissæ are taken either as $x$, the number of atoms of carbon contained in a unit of the allny, composed of a hundred atoms, or as $y$, the number of molecules of cementite $\mathrm{Fe}_{3} \mathrm{C}$ contained in a unit of the alloy composed of a hundred molecules, and assuming an iron molecule to contain two atoms. The author has used for his data the experimental results obtained by Carpenter and Keeling fifteen years ago, which are generally accepted as valid for the liquidus of the series. He comes to the conclusion that whether Raoult's law of the depression of the freezing point or the more general law expressed by the Le ChatelierSchroeder formula

$$
l s=\frac{\mathrm{Q}}{2}\left(\begin{array}{c}
\mathrm{I} \\
\mathrm{Y}
\end{array}-\frac{\mathrm{J}}{\mathrm{i}}\right),
$$

where $T$ is the absolute temperature and $z$ is the number of molecules in the solvent contained in a unit of the alloy forming a single molecule, be adopted, the calculated figures agree, decidedly better with the experimental results on the iron-cementite than the ironcarbon hypothesis. Further, the results which agree best are obtained on the assumption of a rectilinear variation afforded by the $\mathrm{Fe}_{3} \mathrm{C}-\mathrm{Fe}_{2}$ hypothesis.

In the second paper Prof. Honda, of the Toholsu Imperial University, Sendai, Japan, returns to a consideration of the allotropic forms of iron. It is now generally agreed that pure iron undergoes two transformations between the freezing point and the ordinary temperature, which are allotropic. The first of these is the $\mathrm{A}_{4}$ transformation, and takes place at $\mathrm{I} 394^{\circ} \mathrm{C}$., about $130^{\circ}$ below the freezing point. It is completed in a few minutes. The second is the $A_{3}$ transformation, and occurs at about $900^{\circ} \mathrm{C}$. This transformation, although not so rapid as the previous one, can be completed in a very narrow temperature interval, provided the heating and cooling are sufficiently slow. In a recent experiment by Ishiwara, where the complete transformation required about three hours, the difference between the $\mathrm{Ac}_{3}$ and $\mathrm{Ar}_{3}$ points did not exceed $5^{\circ} \mathrm{C}$.

The $A_{2}$ change is of a different nature. It does not take place at a definite temperature or within a small range, but begins at the ordinary temperature, its rate becoming greater as the temperature is increased, until it is completed at $785^{\circ} \mathrm{C}$. The various physical properties, such as heat absorption or evolution, intensity of magnetisation, electrical resistance, thermal conductivity, etc., vary similarly with one another, the values changing slowly at lower temperatures, and the change becoming faster as the temperatures approach $78_{5}^{\circ} \mathrm{C}$. When thermal equilibrium is established the change in any one of the properties does not increase by a prolonged heating. The properties are definite functions of the temperatures. It is this distinction. according to the author. which constitutes the essential difference between allotropic and non-allotropic changes. According to him, therefore, an allotropic change is the transformation of a substance from one phase to another which proceeds at a definite temperature if sufficient time be allowed for the transformation.

The $\mathrm{A}_{2}$ critical point, as determined thermally, is usually taken as $768^{\circ} \mathrm{C}$. This is the temperature at which the rate of heat evolution or absorption is at No. 2596, VOL. TO3] the maximum on cooling and heating respectively. This figure is somewhat lower than $785^{\circ} \mathrm{C}$., which is the value proposed by Honda, and is the temperature at which the $\mathrm{A}_{2}$ transformation begins on cooling and terminates on heating.

In the case of carbon steels, in addition to the above, there are two other transformations, $A_{1}$ and $A_{0}$. The former is a change of phase, while the latter is a change in cementite of a similar nature to $A_{2}$. Accordingly, whereas $A_{4}, A_{3}$, and $A_{1}$ are phase changes, the $A_{2}$ and $A_{0}$ transformations extend from the critical to the lowest temperature. Every stage of these changes is a definite function of the temperature, and, from the point of view of the molecular theory of magnetism, they may be regarded as processes in which the molecules acquire rotational energy about their magnetic axes.

\section{H. C. H. Carpenter.}

\section{SEX, REPRODUCTION, AND HEREDITY IN PIGEONS AND FOWLS.}

$\mathrm{D}^{\mathrm{R}}$. OSCAR RIDDLE has previously brought forward evidence to show that male pigeons arise from eggs (yolks) of less storage metabolism, which implies small size and higher (oxidising) metabolism, and that females arise from eggs (yolks) of greater storage metabolism, which implies large size and lower (oxidising) metabolism. He has now (Journ. Exper. Zoology, vol. xxvi., I9I8, pp. 227-54) studied two cases of female "identical twins," and seeks to show that the ova (yolks) which produced both of them were extraordinarily and atnormally large.

Of course, the yolk of an egg cannot be directly weighed on a balance and then put back to see what it will develop into; Dr. Riddle's evidence is necessarily indirect. The eggs when laid were very large compared with all the other eggs produced by the particular parents (totals of 116 and I34 eggs). Double-yolked eggs in doves are practically restricted in their production to hybrids from wider crosses, or to birds showing striking reproductive abnormalities, or to both of these, and would not be expected to appear in the series in which the two cases of "identical twins" were found.

It is suggested that the blastoderm-borders will be abnormally raised in extraordinarily large eggs, and abnormally lowered in extraordinarily small ones, and that this might lead, for physical reasons; to the establishmerit of two independent foci of development. If male "identical twins" were found developing from a very small egg. it would be an interesting corroboration of the author's theory. Meanwhile, he thinks that the available data point to the conclusion that each pair of female "identical twins" arose from a single ovum of high storage metabolism.

In healthy doves and pigeons the right testis is larger than the left in a very high percentage of cases, vet in the female it is the left ovary that persists. The left testis more nearly approaches the ovary than does the right. In disease, particularly in tuberculosis, the testes undergo extreme atrophy, but more in the right than in the left; the ova:y does not seem to suffer reduction in size. The right testis of the very voung birds (from embrvos to squabs a few weeks old) is normally longer than the left. The single (persistent) left ovary of voung female squabs is twice, or more than twice, as long as is either testis in males of similar age (three to seven weeks). Now Dr. Riddle finds (Anat. Record, vol. xiv., Iq 8 , pp. $28_{3-}$ 3.34) that in hybrids the normal size relations of the two testes are often disturbed, sometimes reversed, approximating to the female condition. The number 
of such reversed cases increases as the width of the cross. The excess of males from such crosses is also known to increase similarly, e.g. when the crosses are between members of different genera. The theory suggested is that "sex has been controlled in these forms, and that a male which is forced to arise from a female-producing egg may show in the relative size of its gonads an approximation to the relative size of the gonads of a female."

In an investigation (Journ. Biol. Chem., vol. xxxiv., I9I8, pp. I6I-70) of the correlation between fat content in the blood of fowls and the total egg records, Dr. Riddle and Mr. J. Arthur Harris find a progressive change; it is positive for birds in a laying condition, sinks to zero after the cessation of laying, and finally takes a high negative value in birds which have long ceased to lay. At the end of the first laying vear birds which have laid larger numbers of eggs and are still laying have a higher percentage of fat in their blood than laying birds which have made a poor record for the year. But birds which have laid a large number of eggs and exhausted their fertility have a smaller percentage of fat in their blood than non-laying birds which have poor egg records. Thus the correlation changes from a positive to a negative relationship. This conclusion. involves a serious criticism of that reached by Warner and Edmond (Journ. Biol. Chem., vol. xxxi., 1917, p. $28 \mathrm{I}$ ).

Dr. Riddle and Mr. Carl E. Anderson (Amer. Journ. Physiol., vol. xlvii.: 1918, pp. 92-102) gave ring-doves small doses of quinine sulphate, and found a marked reduction in the yolk size and total size of the eggs. It is well known that quinine reduces the destruction of nitrogenous components of the tissues, and probably checks the secretory activity of the oviduct, the product (albumen) of which is entirely of a protein nature. Furthermore, the presence of quinine in the yolk of the eggs probably checlss the characteristic transformation of the nitrogenous compounds; the eggs are poor in volk for some weeks after the dosage is discontinued.

From an egg produced by a pigeon under the weakening influence of "reproductive overwork" there was hatched in Igra a female bird which might be called an ataxic mutation. Dr. Riddle describes the bird (Proc. Soc. Exper. Biol. and Med., vol. xv., I9I7, pp. . 56-58), which showed when young a marked lack of power over the voluntary movements of the head and body. The affected female was bred to two different males, and the derangement was seen through four generations descended from either. Of I 75 voung ones reared to the age at which the disorder might be exhibited. I I9 were classed as normal and 46 as affected. With some irregularities the character appears like a Mendelian recessive

In an interesting study of the brains of the "ataxic" pigeons (Amer. Journ. Physiology, vol. xlvii., Ior8, pp. I24-36), Miss Mathilda L. Koch and Dr. Riddle report that, as compared with normal birds of the same parentage, there are increased values for moisture. protein, and extracted sulphur, and decreased values for lipoids, phosphatides, and cholesterol. The results of the analvses are interpreted as suggesting a chemical under-differentiation or immaturity of the disordered brains.

Dr. Riddle and Mr. Victor K. La Mer report (Amer. Journ. Phwsiol., vol. xlvii., I9I8. pp. I03-23) a remarkable fact which must be considered in connection with theories of colour-inheritance, namely, the postmortem formation of melanin in the pigmentless retinas and choroids of embryo white ring-doves of $3-12$ davs of development. Killing the tissues in $\mathrm{HgCl}_{2}$ does not prevent the production of the pigment, but the presence of free oxygen is necessary.
INDUSTRIAL LIGHTING.

I $N$ his lecture at the British Scientific Products Exhibition on July 28, Mr. L. Gaster traced the growth of interest in industrial lighting, which had now come to be regarded as essential to the health of the workers, to the avoidance of accidents, and to efficient work. The extension of night-work during the war and the great demands made on British factories had rendered good artificial lighting specially important; and various factors likely to operate in the future, such as the fuller use of the "three-shift" system and the development of the manufacture of accurately made standardised and interchangeable parts, also tended in the same direction. Another important consideration at present was the saving in fuel that might be brought about by the general use of more scientific and efficient methods of lighting, whereby the consumption of gas or electricity necessary to produce a given illumination on the work could be reduced. The case for adequate industrial lighting, both from the economic and humanitarian points of view, was very strong. There was no doubt that both the output and the quality of work suffered if the illumination was defective. Cases were on record in which the output had increased by $8-27$ per cent., and even more, when the illumination was improved. In general, the cost of lighting formed only a small proportion (often less than I per cent.) of the wages bill, so that even a small gain in output more than compensated for the expenditure on good lighting.

Mr. Gaster also gave an instructive account of the steps taken by various Governments in Europe to promote better industrial lighting in the years immediately preceding the war. The French Government had nominated a Committee to inquire into the subject, and the Belgian Government had also been asked to do so. In these cases action had been inevitably delaved by the war, but the Departmental Committee on Lighting in Factories and Workshops, appointed by the British Government in I9I3, had persevered with its labours, and issued a most instructive and valuable interim report in 1915 . In this matter Great Britain might justly claim to have taken the lead in comparison with other nations. During the war, however, the United States, profiting by European experience, had been very active, and there were now five States which actually possessed codes of industrial lighting in force. Experience had shown that managers of factories were quite willing to adopt the recommendations in these codes. their chief desire being to receive assistance and guidance in bringing their illumination un to date. To the worker likewise good illumination was of direct personal benefit. Mr. Gaster expressed the hope that definite reference to adequate industrial illumination would be introduced into the British Factory Act in the near future. It was also desirable that industrial lighting should be included amongst the conditions of work to receive international treatment, so that there might be interchange of experience and uniformity of action in the chief countries of the world.

\section{THE ROYAL SOCIETY OF CANADA.}

$\mathrm{THE}$ sessions of the Royal Society of Canada were held as usual in Ottawa on May 19-22, and were of more than ordinary interest. There was an unusually large attendance of fellows from the various provinces, from British Columbia in the west to Nova Scotia in the east, and the presidential chair was occupied by the Hon. Rodolphe Lemieux, M.P., the distinguished French-Canadian statesman and jurist. Many fellows present had just returned from Europe, 